Check for updates

The BMJ

Cite this as: BMJ 2021;373:n1164 http://dx.doi.org/10.1136/bmi.n1164 Published: 06 May 2021

\title{
Covid-19: Two doses of Pfizer vaccine are "highly effective" against infection, hospital admission, and death, study finds
}

\section{Gareth lacobucci}

Two doses of the Pfizer-BioNTech covid-19 vaccine provide more than $95 \%$ protection against infection, hospital admission, and death, including among older people, a peer reviewed study from Israel has found.

A single dose of the Pfizer vaccine was associated with $58 \%$ protection against infection, $76 \%$ against hospital admission, and $77 \%$ against death, the study published in the Lancet reported. ${ }^{1}$ The findings also indicate that vaccine coverage was the "primary driver" in reductions in covid-19 infections in Israel, not lockdown, the researchers said.

Lead author Sharon Alroy-Preis of the Israel Ministry of Health, said, “These insights are hugely important because, while there are still some considerable challenges to overcome, they offer real hope that covid-19 vaccination will eventually enable us to control the pandemic.” Israel, which currently has the highest proportion of its population vaccinated against covid-19, is the first country to report national data on Pfizer's vaccine.

The observational study used national surveillance data from 24 January to 3 April 2021 to estimate the effects of two doses of the vaccine. Data was analysed in groups based on participants' age. The average follow-up time for people who received two doses was 48 days.

By 3 April 2021, $72 \%$ of people over 16 years ( 4714 932 of 6538911$)$ and $90 \%$ of people over $65(1015620$ of 1127965 ) had received two doses of the vaccine. In the period analysed, Israel had 232268 confirmed covid-19 infections, 7694 hospital admissions (4481 severe and 188 critical), and 1113 deaths. Hospital admissions were classified as severe if patients had a resting respiratory rate of $>30$ breaths per minute, oxygen saturation on room air of $<94 \%$, or a ratio of $\mathrm{PaO}_{2}$ to $\mathrm{FiO}_{2}$ of $<300$. They were classified as critical in the event of mechanical ventilation, shock, or cardiac, hepatic, or renal failure.

Two thirds of infections (66.6\%; 154648 of 232 268) occurred in people over 16 years, and most (94.5\%; 8006 of 8472 tested) were estimated to be the B.1.1.7 UK variant.

Seven days after a second dose, the Pfizer vaccine provided everyone aged over 16 with $95.3 \%$ protection (95\% confidence interval 94.9 to 95.7) against infection, $97.2 \%$ (96.8 to 97.5) protection against hospital admission overall, $97.5 \%$ (97.1 to 97.8 ) protection against severe and critical hospital admission, and $96.7 \%$ protection (96.o to 97.3 ) against death. By 14 days after the second dose, protections for everyone over 16 increased to $96.5 \%$ (96.3 to 96.8) against infection, 98.0\% (97.7 to 98.3) against hospital admission overall, $98.4 \%$ (98.1 to
98.6) against severe and critical hospital admission, and $98.1 \%$ (97.6 to 98.5) against death.

People over 85 had $94.1 \%$ (91.9 to 95.7) protection against infection, $96.9 \%$ (95.5 to 97.9) against hospital admission, and $97 \%$ (94.9 to 98.3) against death seven days after their second dose. Those aged 16-44 had 96.1\% (95.7 to 96.5) protection against infection, $98.1 \%$ (97.3 to 98.7) against hospital admission, and $100 \%$ against death.

Protections were considerably lower between seven and 14 days after receiving the first dose compared with two doses, with $57.7 \%$ (54.9 to 60.3) protection against infection, $75.7 \%$ (72.0 to 79.0) against hospital admission, and $77.0 \%$ (69.7 to 82.6) against death. The authors said that this emphasised the importance of fully vaccinating adults, noting that little was known about the duration of protection of one dose compared with two doses.

The researchers also identified a public health benefit to vaccination, observing correlations between declines in infections and high vaccine uptake for each age group, rather than an association with the beginning of Israel's lockdown on 27 December. Infections among over 65 year olds continued to rise until mid January, peaking at around 55 cases per 100 ooo. But infections started to decline as people began receiving their second vaccine doses, with daily cases of around 30 per 100 ooo by the first phase of reopening on 7 February.

The number of daily infections continued to decline as more people received the vaccine, with steeper and swifter declines observed for people over 65 . This reflected higher and earlier vaccination rates among older people, but similar patterns were identified in all age groups.

The authors acknowledged some limitations to their study including differences to vaccine rollout in different countries and the emergence of new variants.

In a linked commentary, Eyal Leshem of the Chaim Sheba Medical Centre, Israel, and Annelies Wilder-Smith of the London School of Hygiene and Tropical Medicine, who were not involved in the study, wrote, “Israel's experience provides impetus for countries to proactively pursue high vaccine coverage to protect the population; however, rollout would need to follow the WHO prioritisation roadmap to maximise the public health impact, in light of vaccine supply constraints."2

Haas EJ, Angulo FJ, McLaughlin JM, etal. Impact and effectiveness of mRNA BNT162b2 vaccine against SARS-CoV-2 infections and COVID-19 cases, hospital admissions, and deaths following a nationwide vaccination campaign in Israel: an observational study using national surveillance data. Lancet 2021; doi: 10.1016/S0140-6736(21)00947-8. 
2 Leshem E, Wilder-Smith A. COVID-19 vaccine impact in Israel and a way out of the pandemic. Lancet 2021; doi: 10.1016/S0140-6736(21)01018-7.

This article is made freely available for use in accordance with BMI's website terms and conditions for the duration of the covid-19 pandemic or until otherwise determined by BMJ. You may use, download and print the article for any lawful, non-commercial purpose (including text and data mining) provided that all copyright notices and trade marks are retained. 